DOI 10.37882/2223-2982.2021.10.03

\title{
ТЕОРЕТИКО-МЕТОДИЧЕСКИЕ АСПЕКТЫ ФОРМИРОВАНИЯ КУЛЬТУРЫ ВОКАЛЬНОЙ РЕЧИ У ОБУЧАЮЩИХСЯ НА ЗАНЯТИЯХ ХОРОВОГО КЛАССА
}

\section{THEORETICAL AND METHODOLOGICAL ASPECTS OF FORMATION OF THE CULTURE OF VOCAL SPEECH BY STUDENTS AT THE CLASSES OF THE CHORAL CLASS}

\section{Z. Alieva}

Summary: Purpose: the author considers the culture of vocal speech as the most important part of the choral culture, reflecting the culture of speech of different peoples. Tasks: consider choral music and offer guidelines for mastering the elements the art of vocal speech and the systematization of its patterns in singing. Methods: the author considered the basic provisions of the technique of vocal speech, its techniques and exercises. Hypothesis: the degree of expressiveness of the word in singing only then acquires emotional expressiveness when it fully reaches the listener. As a result of the work, the author offers recommendations for mastering the closest connection between the nature of the formation of phonemes and the quality of vocal sound, established scientific research in the field of orthoepy and conditions that help voice formation, the work of the vocal apparatus and speech organs.

Keywords: choral culture, speech culture, choirmaster, musical image, artistic and technical elements, vocal pronunciation, articulation, vocal diction, orthoepy, phonemes, vocal apparatus, speech apparatus.
$\mathrm{H}$ а занятиях хорового класса обучающийся развивает не только организаторские способности, волю, умение находить психологический и творческий контакт с каждым из участником хора и коллектива в целом, но и приобретает практические навыки ориентации в общей хоровой звучности, учится слушать и чувствовать все хоровые партии, а также анализировать качество звучания с точки зрения культуры вокальной речи в хоровом пении, как наиболее эмоциональнодейственном способе выражения поэтического текста в вокально-хоровой музыке. Поэтому, учитывая большую роль слова в пении, важной задачей каждого хормейстера - научить певцов хора культуре вокальной речи.

Отдельные аспекты вокальной речи раскрывались в работах представителей вокального искусства (певцов и вокальных педагогов), а также рассматривались в разделах акустики и физиологии. Некоторые вопросы, касающиеся фонетической природы вокальной речи, описаны в специальной литературе, в том числе в работах, авто-

\author{
Алиева Зарема \\ К.п.н., дочент, ГБОУ ВО Республики Крым \\ «Крымский инженерно-педагогический университет \\ имени Февзи Якубова», г. Симферополь \\ alieva@mail.ua
}

Аннотация: Цель: автор рассматривает культуру вокальной речи как важнейшую часть хоровой культуры, отражающую культуру речи разных народов. Задачи: рассмотреть хоровую музыку и предложить методические рекомендации по освоению элементов искусства вокальной речи и систематизации ее закономерностей в пении. Методы: автором были рассмотрены основные положения техники вокальной речи, ее приемов и упражнений. Гипотеза: степень выразительности слова в пении только тогда приобретает эмоциональную выразительность, когда оно всецело доходит до слушателя. В качестве результатов работы автор предлагает рекомендации по овладению обучающимися теснейшей связи между характером образования фонем и качеством вокального звучания, установленными научными исследованиями в области орфоэпии и условий, помогающих голосообразованию, работе голосового аппарата и органов речи.

Ключевые слова: хоровая культура, культура речи, хормейстер, музыкальный образ, художественно-технические элементы, вокальное произношение, артикуляция, вокальная дикция, орфоэпия, фонемы, голосовой аппарат, речевой аппарат.

рами которых являются языковеды [3, с. 6].

Специфика вокальной речи в пении заключается в умении выразительно, правильно в вокальном звучании передать музыкальный образ произведения.

Искусство вокальной речи, ее культура, как и искусство пения в целом, состоит из двух неразрывных элементов: технического и художественного. Для лучшего освоения каждого из этих элементов, систематизация закономерностей вокальной речи в пении также состоит из технической и художественной частей. Культура вокальной речи в пении, как и каждое искусство, без технического умения не существует. Технически неподготовленный певец не может овладеть художественной вершины вокального искусства [3, с. 8].

Приступая к изучению основных положений техники вокальной речи, ее приемов и упражнений, следует осознать, что: 
- основные технические навыки нужно осваивать с самого начала работы над голосом, произношением, культурой тела и другое, работая не периодически, а систематически, на протяжение всей творческой жизни;

- приобретенные в техническом тренаже новое только тогда можно считать освоенным, когда оно станет привычным;

- техническая работа над физическими процессами не может проводиться в отрыве от психологического процесса, так как физическая сторона пения неотделима от психологической [4, с. 6].

Каждый вокальный звук должен четко и рельефно оформляться в речевой «лаборатории» в ту или другую фонему.

Активные органы речи - язык, губы, мягкое небо, нижняя челюсть, берущие действенное участие в образовании фонем и представляют собой совокупность мышц, благодаря чему имеют возможность сокращаться, то есть менять свою форму.

К пассивным принадлежат органы с твердой массой, которая не позволяет им двигаться и менять свой размер и форму. Пассивные органы - верхнее небо, верхняя челюсть, зубы и их альвеолы - выполняют вспомогательную роль.

В речевой работе иногда берут участие лишь активные органы. Например, «м» произносится только губами.

Со временем речевые органы выполняют роль пассивных. Например, звук «к» произносится приближением задней части языка - мягкому небу, которое в данном случае почти неподвижное.

Активные органы речи должны работать чрезвычайно четко и точно. Наименьшее отклонение от необходимого направления приводит к другой фонетической окраске. Так, расположение языка по твердому небу дальше от верхних зубов ведет до произнесения не «л» (твердого) а «ль» (мягкого).

Особенно нужна точность движений активных речевых органов в пении, когда язык и губы должны мягко, при этом четко «вырисовывать» гласные, которые «тянутся». Каждая неточность вокального гласного негативно отражается на голосовом звучании, мешая четкости и доходчивости вокального текста.

Какие же причины снижают качество вокальной дикции?

Качество вокальной дикции может быть снижено по нескольким причинам. Приведем основные из них: аномальное строение речевого аппарата; нарушение работы речевого аппарата из-за болезни отделов нервной системы, управляемых его функцией; незнание или недостаточно четкое знание структуры и физиологии речевого апnарата; неправильное голосовое звучание; неразвитость речевого аппарата или его отдельных органов; манерность.

Речевые органы, которые берут участие в оформлении звуков гортани в звуки речи, должны быть максимально подвижными. Плохо развитые или недостаточно подвижные речевые органы бывают причиной многих речевых дефектов (например, сюсюканья, шепелявости и др.). Итак, развитие речевых органов певца, как и развитие рук и пальцев пианиста, требует уделять большое внимание. Здесь к слову напомнить слова К.С. Станиславского о «муштре» и «тренинге» органов речевого аппарата: «...как можно лучше развивайте артикуляцию губного аппарата, языка и тех частей, оттачивающих и оформляющие согласные. В этом процессе большую роль играют мускулы, которые требуют систематического развития...» [2, с. 87].

Работая над развитием речевых органов, необходимо добиваться точных и четких движений этих органов и следить, чтобы качество вокального звучания на протяжении всего упражнения не менялось.

\section{Упражнения Аля развития ниґней челюсти}

Певцу прежде всего надо свободно и достаточно (с учетом индивидуального строения голосового аппарата) раскрывать рот. Скованность движений нижней челюсти часто тормозит воспитание голоса, а также и совершенствование вокальной дикции.

Для развития движений нижней челюсти рекомендуется вокальное упражнение - по полутонам вверх и вниз (октава и более) на гласном «а», которая требует наибольшего раскрытия рта и его объема: ааа....

Материалом для следующих упражнений по этому заданию может быть соединение гласного звука - a c o или ц, даже с $\underline{\text { n: }}$

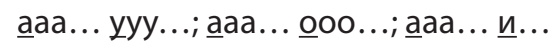

Первый гласный - а слегка акцентируется.

Эти упражнения, развивая мышцы нижней челюсти, уточняют степень опускания ее и характер самих движений на данных вокальных гласных. Для большего ощущения движения нижней челюсти в начале упражнений надо делать вдох после каждого полутона, далее можно и реже.

Упражнения м^я развития мышш губ 
Эти упражнения имеют целью вызвать ощущения необходимого рабочего натяжения губ и развития движения и пружинистость их, особенно верхней губы. Проводятся они губами на гласные $y, \underline{o}$, а также $\underline{u}$.

На гласном ұ или о губы (с помощью данного гласного) довольно плавно вытягиваются вперед:

ууу...; ооо...

Вокальное й своей артикуляцией растягивает губы в стороны.

Далее последние упражнения объединяются:

ууу... иии; ооо... иии

иии... ууу; иии... ооо...

\section{Упражнения на развитие мышш языка}

Для развития подвижности мышц языка прорабатываются упражнения на слоги ла, ло, ли, а также другие комбинации согласных и гласных.

Каждое из приведенных упражнений является только образцами для некоторых заданий. Их можно усовершенствовать, менять темп, ритм, характер исполнения и т.п. Полезность этих упражнений обусловливаются тем, что они вырабатывают вокальное звучание, вокальную артикуляцию речевых звуков строго в ритме. Таким образом, педагог-вокалист может включить их в свою работу с некоторыми усложнениями и сменами темпа, ритма и т.п.

\section{К^ассификация г^асных}

Точное знание классификации гласных в такой же мере необходимо каждому певцу, как и четкое представление о месте данной ноты на нотном стане, о регистровом и тембровом решении вокального звучания и других вокально-музыкальных вопросов.

Гласные звуки различаются по месту и по способу их образования.

По месту образования гласные, в зависимости от того, какая часть языка (передняя, средняя или задняя) относится к соответствующему (передней, средней или задней) отделу неба, то есть в зависимости от места нахождения языка, разделяются на передние (русские $\underline{\underline{u}} \underline{\underline{\exists}}$, крымскотатарские $\underline{n}, \mathbf{y}$ ), средние (русские ы, крымскотатарские $\underline{\exists}, \underline{\text { o) }}$ и задние (русские $\underline{a}, \underline{0}, \underline{y}$, крымскотатарские $\underline{a}, \underline{o})$.

По способу образования, то есть по степени соотношения языка к небу, гласные подразделяются на верхние или узкие (русские $\underline{a}, \underline{b}, \underline{y}$, крымскотатарские $\underline{u}, \underline{y}$, bl,

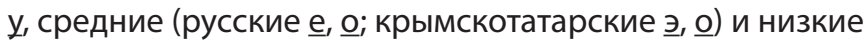
(русские $\underline{a} ;$ крымскотатарские $\underline{a}, \underline{o}$ ).
По величине ротовой полости, которая требует образования гласных, они идут в таком порядке (начиная с наименьшей величины раскрытия):

русские гласные - y, о, и, ы, э, а

крымсктатарские - a, o, у, ы, и

По порядку увеличения ротового пространства при произношении гласных они располагаются так:

русские гласные - и, ы, э, у, o, a

крымскотатарские и, ы, e, y, o, a

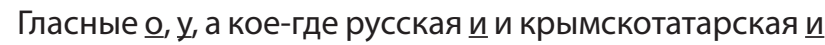
воспроизводятся с активным участием губ и называются лабиализованными.

\section{Типовая артикуляшия гласных}

Типовую артикуляцию каждого гласного звука можно охарактеризовать так:

Звук а русский и крымскотатарский. Нижняя челюсть опущена. Ротовая щель больше, чем при образовании других гласных. Язык из спокойного состояния слегка притягивается назад и едва поднимается к заднему мягкому небу. Передняя часть его «плосковата», с продолженным углублением, кончик почти касается нижних зубов. Все тело языка как будто опускается на дно рта.

Звук и русский, и крымскотатарский. Рот слегка раскрытый, ротовая щель уже, чем при образовании других гласных. Язык максимально поднят в своей передней части и почти соприкасается с передней частью твердого неба. Кончик его касается нижних зубов. Слегка натянутые губы немного растянуты в стороны.

Звук 히 русский отличается от крымскотатарского большим опущением нижней челюсти и, таким образом, большим раскрытием рта. Язык почти задней частью поднимается и притягивается назад, нижняя губа слегка опускается.

Звук э русский и крымскотатарский. Рот раскрыт в вертикальном направлении больше, чем при произношении ‥ Передняя часть языка поднимается вверх и вперед, но ниже и глубже, чем, когда произносят ‥ Конец языка - за нижними зубами.

Звук о русский и крымскотатарский. Форма рта овальная. Корень языка немного поднимается в направлении к мягкому небу. Конец языка втянут к нижним зубам. Губы растянуты и выступают вперед.

Звук у русский и крымскотатарский. Форма рта овальная. Отверстие его меньше, чем при образовании o, губы более сближены и выступают вперед «воронкой». Нижняя челюсть опускается вниз. Язык отступает назад и задней частью поднимается в направлении к мягкому 
небу. Конец его еще больше притягивается назад, чем при образовании о.

Типовое произношение каждого гласного является артикуляционной основой, на которую внутренние переживания накладывают множество интонационных красок. Каждая из таких окрасок вызывает соответствующие артикуляционные оттенки. Однако типовая артикуляция, артикуляционный скелет остается неизменным, что имеет принципиальное значение для линии вокала.

\section{Спешифика артикулячии вокальных гласных}

Каждому вокальному гласному соответствует индивидуальное положение артикуляционных органов при единстве речевого гласного. Таким образом, артикуляция вокальных гласных принципиально не отличаются от артикуляции речевых гласных, однако между ними существуют некоторые отличия, а именно:

- артикуляционная установка вокальных гласных внешне значительно больше «отточена» и округлена, чем речевой;

- рото-глоточный путь прохождения потока воздуха подчинен требованиям вокального звучания; это осуществляется в основном энергичнейшим натяжением стенок всего рото-глоточного пути;

- форма и объем резонаторов при произношении вокального гласных четче, чем при проговаривании речевых;

- ротовая полость при образовании вокальных гласных значительно больше, чем при образовании речевых гласных, так как энергичнее укорачивается мягкое небо и больше опускается нижняя челюсть.

Разница артикуляции и вокального голосообразования обуславливают характерные черты вокальных гласных: певучесть, единство, резонантность (лучшие ощущения) и равномерную округлость звучания.

Певучесть вокальных гласных появляется, главным образом, вследствие большей протяженности их в сравнении с речевыми гласными. При правильном строении гласных вокальная речь почти не прерывается и создается впечатление беспрерывного звучания.

Единство, «нейтрализация», то есть приближении звучания одного гласного к другому является по сути подчинением индивидуального звучания гласных требованиям вокального тона и обуславливает вокальный тембр. Однако, эту специфичное единство вокальных гласных ни в коем случае нельзя понимать, как подмену одного гласного другим. Даже при разнородных художественных нюансах все гласные на большей части диапазона сохраняют свои индивидуальные черты [4, с. 66].

Резонирование вокальных гласных проявляется в их большей чувственности в сравнении с речевыми гласными.

Умеренная мягкая округленность звучания придает вокальному гласному полноту и собранность, стирает резкие речевые грани, а также способствует единству тембральной окраски гласных на всем диапазоне. Чрезмерная округленность создает не только слово, но и вокал.

При правильной организации вокальных гласных, указанные черты их способствуют образованию «высокого», «близкого» и «собранного» вокального звучания.

\section{Согласные, их к^ассификашия и физиология}

Согласные звуки различаются на сонорные, звонкие согласные, в которых голос значительно перекрывает шумовые, - наиболее полезные для пения. Это русские $\underline{\pi}$ $\underline{\mathbf{M}}, \underline{\mathrm{H}}, \underline{\mathrm{p}}$, крымскотатарские $\underline{\mathrm{M}}, \underline{\mathrm{H}}, \underline{\mathrm{H}} \underline{\mathrm{z}}, \underline{\Omega}$. При произношении сонорные встречают меньше препятствий, точнее - эти препятствия меньше мешают, нежели при образовании шумовых согласных. Например, при произношении $\underline{\mathrm{M}}$ губы плотно стиснуты, а при произношении н кончик языка, притиснутый к верхним зубам, в обоих случаях воздух проходит через носовую полость; при произношении п кончик языка упирается в переднюю часть верхних мышц, однако воздух проходит на опущенных боках языка. При образовании крымскотатарского 븡 воздух свободно протекает сквозь приближенные губы. Кроме того, на образование сонорных меньше затрачивается выдыхаемого воздуха. А это, в свою очередь, обусловливает меньшее количество шума и, таким образом, способствует значительно большей звучности сонорных в сравнении с шумовыми.

Шумовые согласные делятся на звонкие и глухие.

Русские:

- звонкие - 6, в, г, г (h - согласный г- придыхательный. В русских словах он уживается лишь в призвуках «ага», «ого», «эге». Встречается также в иностранных названиях и прозвищах), д, ж, 3;

- глухие - п, ф, к, х, т, ш, ч, с, ц.

Крымскотатарские:

- звонкие - 6, д, г, (г), гъ, в, в (этот звук встречается только в словах, заимствованных из русского языка), з, ж, й, (гъ), дж,

- глухие - п, т, к, (к), къ, (ф), ф, с; ш, щ (эти фонемы встречаются только в словах, заимствованных из русского языка), х, ц (эта фонема встречается только в словах, заимствованных из русского языка), ч.

Крымскотатарский согласный $\underline{x}$ отличается от соответствующего русского звука тем, что в крымскотатарском языке звук образуется при сближении самой 
задней части спинки языка с концом мягкого неба, а в русском языке - при сближении задней части спинки языка с передней частью мягкого неба [1, с. 44].

Глухие согласные произносятся в большей степени за счет артикуляционного аппарата. Голосовые связки при произношении их расслаблены и почти не колеблются. Большинству звонких согласных соответствуют глухие, указывающие на их родственность. Эти парные согласные звуки произносятся в одном и том же месте речевого аппарата, с помощью одних и тех же органов, почти одними и теми же их частями. Ясно, что в вокальной речи согласные звонкие желательны, чем глухие, так как голос при произношении их не выключается.

Мягкие согласные в сравнении с одноименными твердыми должны при своем образовании дополнительно артикулировать. Они напоминают установку на звук ̆ㅡ (и краткий), так как дополнительное приближение средней части языка к середине твердого неба, в некоторой мере подтягивает к середине неба весь со-

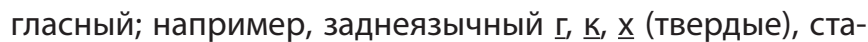
новясь мягкими, направляются вперед к середине неба, а переднеязычные, скажем I, д (твердые), отходят назад к середине неба. При произношении губных мягких, губы примыкают к зубам, язык упирается в нижние зубы, а при проговаривании одноименных твердых согласных этого не бывает; только мягкие $\underline{\underline{p}}, \underline{\underline{w}}$ ㅆ становятся больше передними [1, с. 42].

Взрывные согласные, разрывая звуковой поток, тем самым прерывают и линию вокала. Этот прерывание влияет на пение. Однако, в то же время требует крепкого выдыхаемого толчка, способствующего энергичной подачи и интонационной чистоты звучания. В этом позитивное значение взрывных согласных.

Фрикативные согласные помогают своей фрикацией беспрерывному протеканию вокальной линии, вместе с тем приобщают к ней характерные согласные шумы, тремоляции.

Аффррикаты - наиболее неудобны для вокальной речи. Хотя они являют собой тесное соединение взрывного и фрикативного согласных (или фрикативного и взрывного), но оба согласных больше глухие. К тому же, их сопровождаемая фрикация или шипящая - как при $\underline{4}$ (ш) или свистящая - как при ц (ㄷ).

Принцип тренажной работы над согласными в текстовом материале такой же, как и над гласными.

Русские и крымскотатарские $\underline{\sigma} \underline{\sigma}($ мягкий), $\underline{n} \underline{n}$ (мягкuй).

При артикуляционном образовании $\underline{6}, \underline{6}$ (мягкий) необходимо помнить про лабиальный (губной) характер этих звуков (губы примыкают одна к одной по всей длине) и про то, что 프- глухой звук и образуется без голоса, а $\underline{\sigma}$ - звонкий и в нем к шумам приобщается голос.

В момент образования $\underline{6}, \underline{n}$ цельно замкнутый рот раскрывается выдуванием потока, от чего нижняя челюсть немного отталкивается вниз. Язык - в почти спокойном состоянии.

Мягкие $\underline{6}$ 프 в пении требуют большего рабочего напряжения губ, чем твердые $\underline{6}, \underline{n}$, они требуют еще дополнительного приближения средней части языка, который напоминает артикуляционное движение на й. В общем, все мягкие согласные в сравнении с твердыми требуют активнейшей работы органов, с помощью которых они образуются.

В заключении следует отметить, что произносить слова - вещь очень трудно исполнимая, однако совершенно необходимая. Достигается это следующим образом: гортань на полном дыхании непрерывными и ясными колебаниями рождает звук, и в то же время органы произношения придают этому звуку формы согласных и гласных. От исполнения требуется ясность и выразительность. Ясность исполнения зависит от отчетливого соблюдения метра и ритма, оттенков и фразировки. Выразительность, заключающаяся в верной передаче чувств и настроений, есть венец культуры вокально-речевого искусства.

\section{ЛИТЕРАТУРА}

1. Меметов А. Крымские татары: историко-лингвистический очерк / А. Меметов. - Симферополь: Анаюрт, 1993. - 54 с.

2. Станиславский К.С. Моя жизнь в искусстве / К.С. Станиславский. - Л., Л.: Искусство, 1945. - 544 с.

3. Учебный хор. Учебное пособие / Чергеев А.А., Алиева 3. / Симферополь: «Крымучпедгиз», 2014. - 122 с.

4. Хоровой класс. Учебное пособие / Чергеев А.А., Алиева 3., Сейтмеметова Э.А. / Симферополь: Ариал, 2015. - 168 с.

() Алиева Зарема (alieva@mail.ua). 